\title{
STRENGTH OF FRAME ELEMENTS OF ENERGY OBJECTS UNDER ATMOSPHERIC IMPACT
}

\author{
P.V. Yakovlev ${ }^{1, *}$, and V.A. Lebedev ${ }^{1}$ \\ ${ }^{1}$ Saint-Petersburg Mining University, 2, 21st Line, St Petersburg 199106, Russia
}

\begin{abstract}
The paper considers the issues of strength of energy facilities' load-bearing metal structures under the influence of acoustic waves produced by a lightning strike. The studies were carried out using finite element test models of cantilever beams of various designs. The beams are loaded with the total load of the beams' own weight and the shock wave produced by a lightning strike from a distance of $1 \mathrm{~m}$ from the beams' surface. Calculation results substantiate the necessity to consider the impact of thunder when calculating the structure of energy facilities made of sheet metal. It was revealed that deformations and loads in sheet metal structural elements at the time of a lightning strike from a distance of less than $1 \mathrm{~m}$ from the structure's surface may exceed the acceptable values for the yield strength of structural steels. As a result of the work, recommendations were made on the location of the lightning rods and the need to reduce the operational loads during a thunderstorm.
\end{abstract}

\section{Introduction}

On August 14, 2018, the Morandi Bridge overpass of the A10 Genoa-Savona expressway in Italy, located within the boundaries of Genoa, collapsed. According to TG24COM TV channel's witnesses, the incident occurred after a lightning had struck the bridge. It is obvious that the thunder that accompanies a lightning strike and represents a sound wave of significant amplitude is an additional load on all surfaces on the waves' path. It is obvious that this incident requires a study for the impact of lightning on the elements of critical structures and buildings. First and foremost, those are the energy facilities that pose a significant danger to humans and assure the operation of industrial and civil facilities.

\section{Materials and methods}

Since the impact of thunder on structures is accidental and the probability of destruction is small, there are no experimental data on the effects of thunder on various surfaces. Because of that, the strength calculations of loaded elements of energy facilities and industrial buildings and structures in combination of loads don't take into consideration the impact of a thunder's shock wave. There are separate works [1-9] in which the features of the shock wave formation during a lightning strike are studied. Considering the variety in the designs of elements of buildings and facilities, numerical $3 \mathrm{~d}$ models of elastic cantilever beams were used to study the shock wave. The beams were loaded once by external pressure in accordance with the available data
[10-13] on the pressure level at different distances from the lightning.

\section{Results}

The purpose of this study is to research the impact of thunder on the metal structures of energy facilities when lightning strikes a building or objects located near it. For this purpose, the problems of calculating the residual strength and deformation of the load-bearing metal structures of the two most common types of beams were solved, those types being the lattice beam and the box beam.

It is known that thunder is an acoustic shock wave generated by a channel of heated air. At the distances of $0,5-1 \mathrm{~m}$, the air pressure in the shock front can exceed 1 bar, and in some cases reach 10 bar[1]. The wave frequency depends on the discharge power and air pressure. It is located in the range from 1 to $60 \mathrm{~Hz}$. To calculate the strength of the beams in the model, a pressure of 1 bar was created at the wave front from a single influence on the surface of a wave with a harmonic law of pressure change.

Besides the shock pressure, the beam model is loaded with gravitational forces. The operation loads from the working equipment and thermal stresses were not taken into consideration. The calculations are made for two types of beam fastening: rigid cantilever fastening and symmetrical beam fastening on both sides.

The solution uses a mathematical finite element model consisting of a system with $n$ degrees of freedom, which is represented by a linear matrix equation of motion of the nth order [14-16]: 


$$
\begin{aligned}
& \left([M]_{c}+[M]_{p}\right)\left\{\frac{d^{2} V}{d t^{2}}\right\}+\gamma_{s}([M][K])^{0,5}\left\{\frac{d V}{d t}\right\}+[K]\{V\}=(1) \\
& \left.=\left\{P_{c m}\right\}+\left[P_{\text {out }}\right]-\left([M]_{c}+[M]_{p}\right)\{t t)\right\}
\end{aligned}
$$

where $[M]_{c},[M]_{\partial},[K]$ - the matrices of distributed (p), concentrated (c) masses and the stiffness matrix $\{V(t)\}$ and its derivatives respectively; $\gamma_{3}$ - loss factor.

$$
\gamma_{3}=2 \xi=2\left(\delta_{3}\left[(2 \pi)^{2}+\delta_{3}^{2}\right]^{-0,5}\right) \cong \delta_{3} / \pi
$$

where: $\delta_{3}$ - the logarithmic decrement of damping of vibrations of the bearing structure, $\xi$ - the coefficient of relative damping, which is equal to: $\xi \leq 0,02 \div 0,04$ $\left(\delta_{3}=0,125 \div 0,25\right)$ for steel structures and $\xi \leq 0,05 \div 0,08$ $\left(\delta_{3}=0,32 \div 0,5\right)$ for reinforced concrete. The vectors on the right side of equation (1) are the static and acoustic loads (thunder), in which $\{\oiiint(t)\}$ - one component accelerogram $\left(\mathrm{m} * \mathrm{~s}^{2}\right)$ created by the pressure of a sound wave with a harmonic change in load over time.

\section{Discussion}

Let us consider the results of the solution for a cantilever beam. Fig. 1 shows the results of the research of the beam deformation under the effect of gravitational forces (a) and the deformation from a combination of loads of gravity and acoustic wave (b).

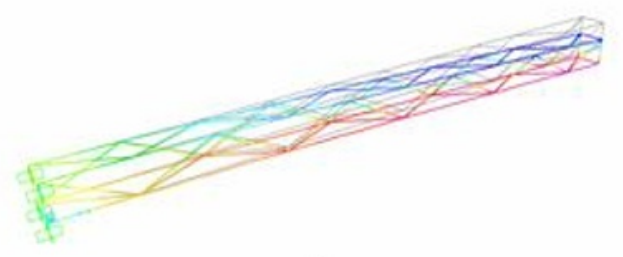

a)

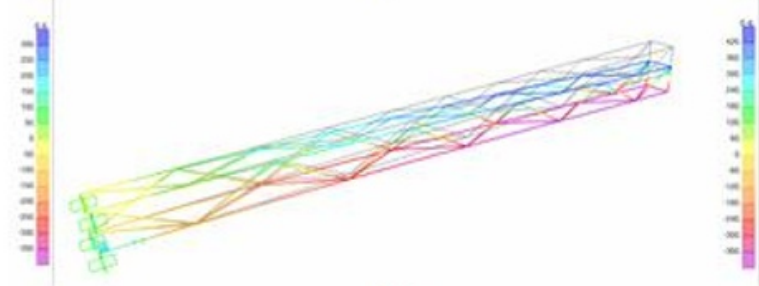

b)

Fig. 1. Deformations of a lattice structure beam, m: a - under the forces of gravity, $b$ - under the effect from a combination of loads.

From the analysis of the calculation results, it follows that the deformations of a cantilever lattice beam are insignificant and do not exceed the acceptable limits when a lightning strikes at a distance of $1 \mathrm{~m}$ from the beam. Fig. 2 shows the stresses in the beam from a combination of shock and gravitational loads, and Fig. 3 shows changes in stresses at the point of fixing the beam after the strike.
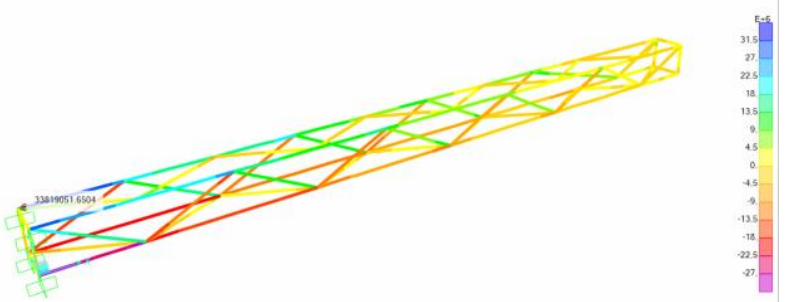

Fig. 2. Stresses in a beam with a combination of shock and gravitational loads, $\mathrm{Pa}$.

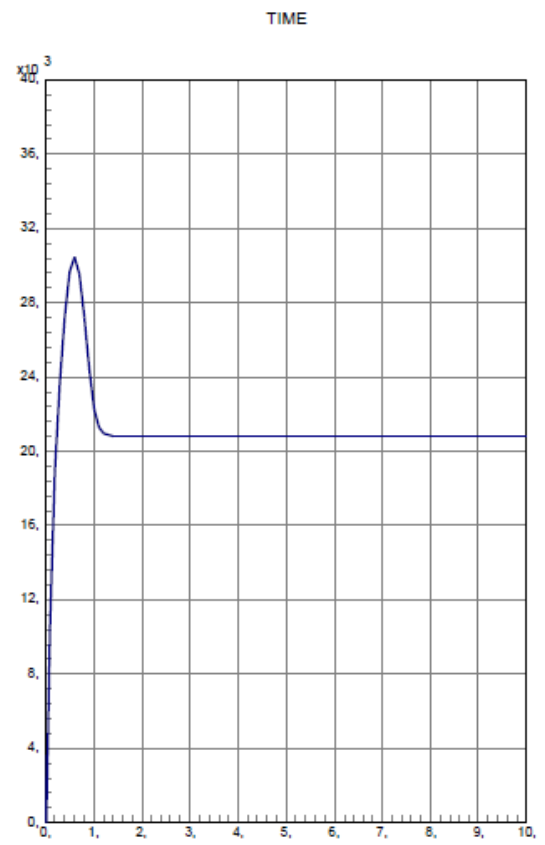

Fig. 3. Changes in stresses at the place of fixing the beam after a lightning strike, $\mathrm{Pa}$.

As can be seen on the graph in Fig. 3, during the transmission of the wave, the stresses increased relatively to the load on the beam from its own weight by $38 \%$. The maximum stress does not exceed $31 \mathrm{MPa}$, so failure is unlikely.

Similar results were obtained for double-sided beam fastening. Fig. 4 shows the change in the stresses in the central part of the beam. 
TIME

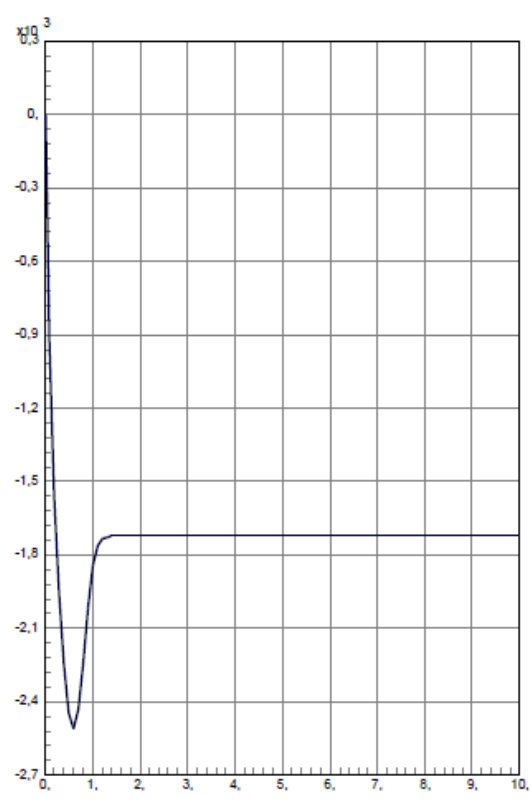

Fig. 4. Changes in stresses over time in the central part of the beam, fixed on both sides after a lightning strike, $\mathrm{Pa}$.

The voltages are within acceptable limits.

Fig. 5 shows the results of calculating the deformation of a sheet steel beam under the effect of gravitational forces (a) and the maximum deformations from the combination of gravitational and acoustic wave loads (b).

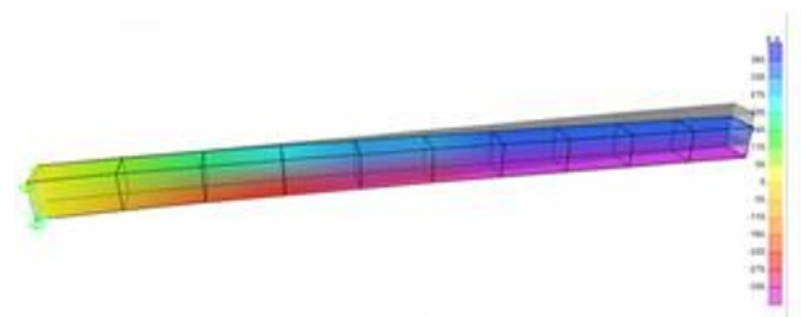

a)

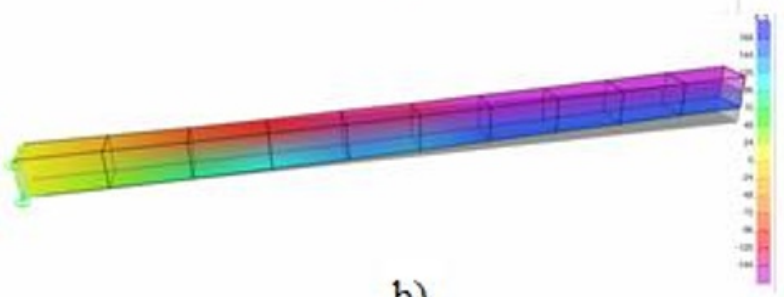

b)

Fig. 5. Deformation of a cantilever-fixed beam made of sheet steel, m: a - under the forces of gravity, b - under the action of a combination of loads.

As seen from Fig. 5, the maximum deformations of the beam exceed $150 \mathrm{~mm}$, which indicates the onset of plastic deformation of the metal with its subsequent destruction. Similar results (Fig. 6) were obtained when analyzing the stress in the metal.

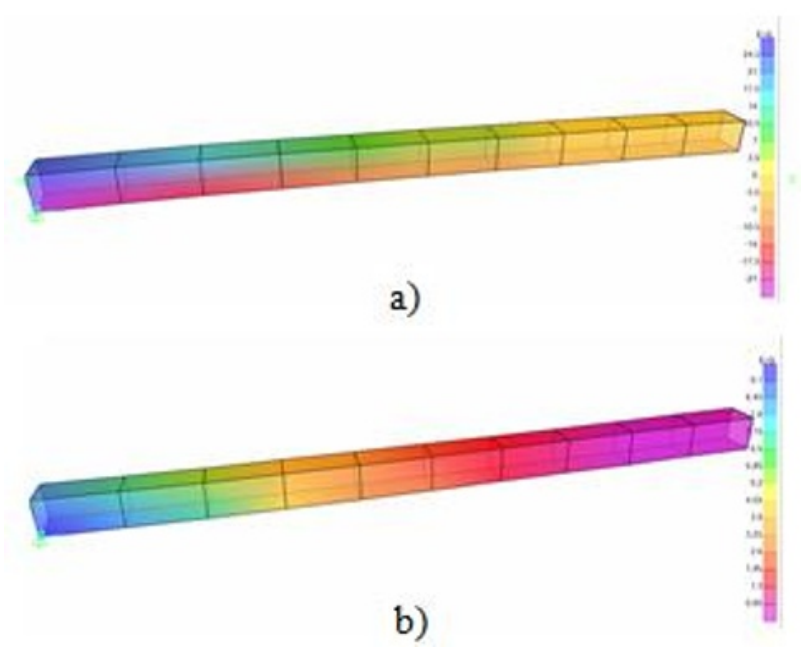

Fig. 6. Stresses in a cantilever-fixed beam made of sheet steel $(\mathrm{Pa})$ : a - under the action of gravity, b - under the effect from a combination of loads.

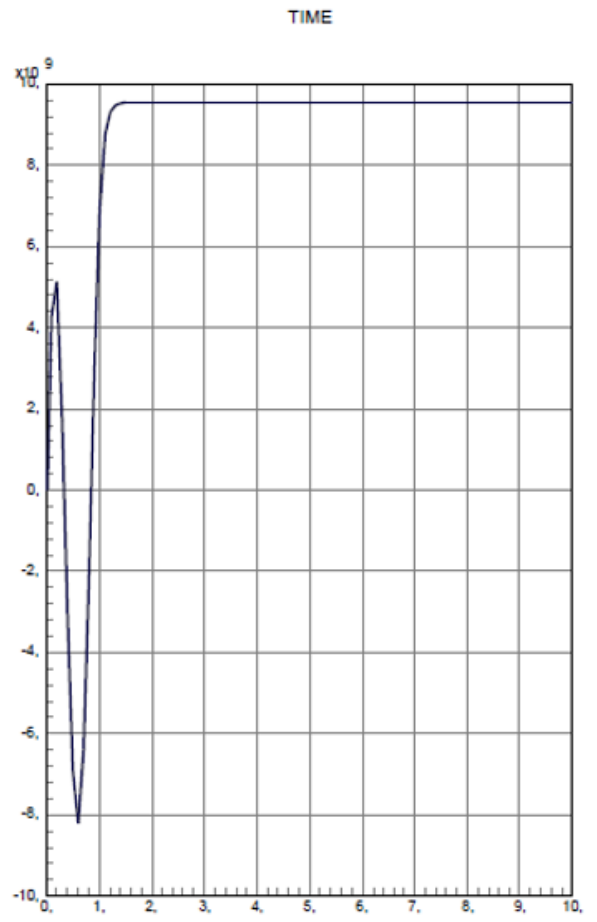

Fig. 7. Changes in stresses over time at the place of cantilever fastening of the beam after a lightning strike, $\mathrm{Pa}$.

As seen on Fig. 7, the stresses in a sheet beam vary in the range from $9 * 10^{9}$ to $-8 * 10^{9} \mathrm{~Pa}$. Those stresses are greater than the yield strength of structural steel $\mathrm{St}$ $20 \sigma_{0}=175 \mathrm{MPa}$, so the beam will be deformed by the shock wave. Similar results were obtained for doublesided beam fastening. 


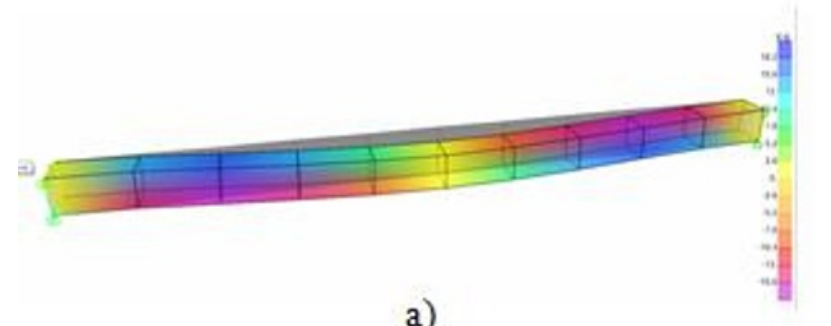

a)

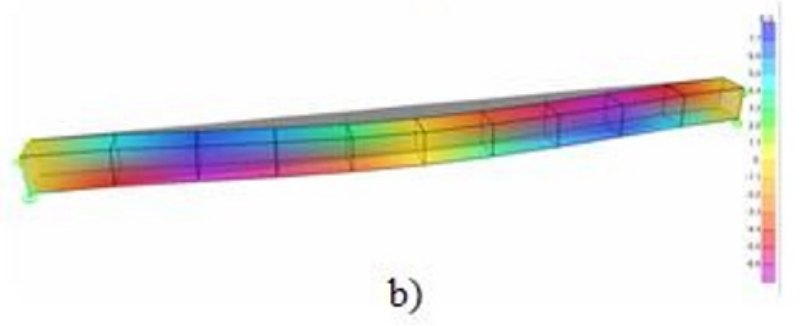

Fig. 8. Deformations of a bilaterally fixed beam made of sheet steel, m: a - under the forces of gravity, b - under the effect from a combination of loads.
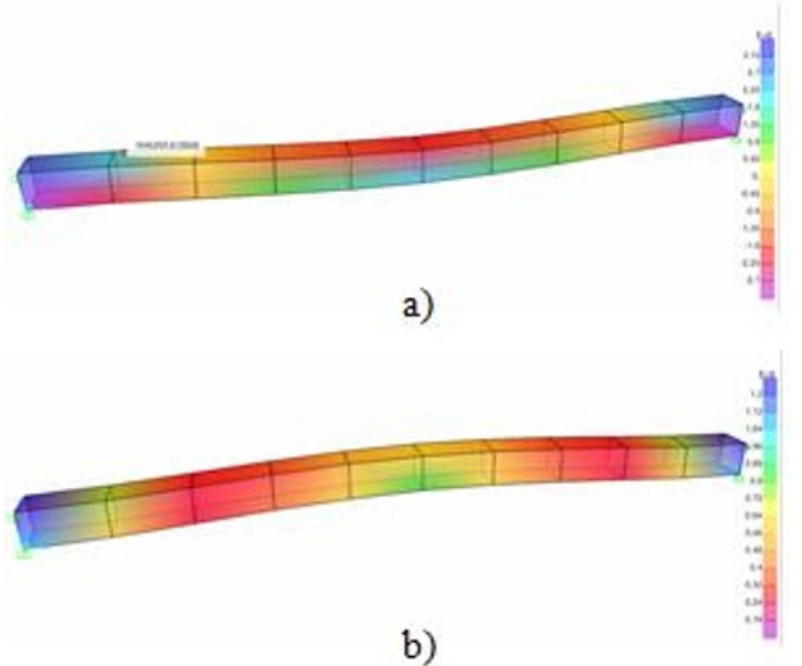

Fig. 9. Stresses in a bilaterally fixed beam made of sheet steel $(\mathrm{Pa})$ : $\mathrm{a}$ - under the forces of gravity, $\mathrm{b}$ - under the effect from a combination of loads.

Because stresses in the metal can reach $800 \mathrm{MPa}$, this will also lead to the destruction of the beam. The greatest stresses in the beam are observed when the beam is deformed upward. This indicates that the highest probability of destruction is due to the occurrence of elastic vibrations and resonance phenomena.

\section{Conclusion}

1. When designing buildings and facilities in areas with a high probability of thunderstorms, in the calculated combination of loads it is necessary to take into consideration the load in a case of a lightning strike.

2. The greatest stresses arise in the load-bearing elements made of sheet steel.

3. Natural vibrations of supporting structures with resonance phenomena increase the probability of structural failure. To increase the stability of structures, it is recommended to install damping elements.
4. The air pressure at the front of the shock wave depends on the distance from the lightning bolt to the beam. In this regard, the distance from the lightning protection to the bearing elements must be at least $5 \mathrm{~m}$.

5. During a thunderstorm, it is advisable to reduce the load on the supporting structural elements.

\section{References}

[1] A. Few, Thunder, Scientific American 223, 1, 8 (July 1975)

[2] A.N. Skripko, The results of studies of lightning protection means with the development of recommendations for reducing the impact of lightning manifestations on buildings, Systems for ensuring technosphere safety: materials of the III All-Russia, scientific conference and schools for young scientists, Taganrog (Taganrog, SFedU, 1415 October 2016) 25-27

[3] A.N. Skripko, V.V. Kobyak, Development of a lightning rod with fixed parameters of the axis of the protection zone, Problems of Technosphere Safety 2015: Materials of the 4th Intern. scientific-practical conf. young scientists and specialists (Moscow, Academy of State Fire Service EMERCOM of Russia, 7-8 April 2015) 231-232

[4] A.Kh. Adzhiev, A.A. Adzhieva, JL.V. Dumaeva, Determination of dynamic characteristics of lightning discharge currents, News of higher institutions, North Caucasian region, Natural sciences 6, 166, 27-30 (2011)

[5] A.Kh. Adzhiev, A.A. Adzhieva, L.V. Dumaeva, Dynamic characteristics of lightning discharge currents, Reports of the Adyg (Circassian) International Academy of Sciences 14, 3, 65 (2012)

[6] G. Malinga, G.A. Malinga, J.M. Niedzweck, Nearshore regional behavior of lightning interaction with wind turbines, Journal of Ocean Engineering and Scienc 1, 1, 66-76 (2016)

[7] D. Saini, D.S. Saini, D. Karmakar, S. RayChaudhuri, A review of stress concentration factors in tubular and non-tubular joints for design of offshore installations, Journal of Ocean Engineering and Scienc 1, 3, 186-202 (2016)

[8] A. Sisodiya, A. Sisodiya, S. Pattnaik, H. Baisya, G.S. Bhat, A.G. Turner, Simulation of locationspecific severe thunderstorm events using high resolution land data assimilation, Dynamics of Atmospheres and Oceans 87, 101098 (2019)

[9] M. Gharaylou, M. M.Farahani, A. Mahmoudian, M. Hosseini, Prediction of lightning activity using WRF-ELEC model: Impact of initial and boundary conditions, Journal of Atmospheric and SolarTerrestrial Physics 210, 105438 (2020)

[10] S. Huang, W. Kong, J. Yang, Q. Zhang, N. Yao, B. Dai, J. Gu, Distinguishing different lightning events based on wavelet packet transform of magnetic field signals, Journal of Atmospheric and Solar-Terrestrial Physics 211, 105477 (2020) 
[11]C. Chatterjee, S. Das, On the association between lightning and precipitation microphysics, Journal of Atmospheric and Solar-Terrestrial Physics 207, 105350 (2020)

[12] M.L. Shmatov, K.D. Stephan, Advances in ball lightning research, Journal of Atmospheric and Solar-Terrestrial Physics 195, 105115 (2019)

[13] S. Motta, A. Montenegro, M. Gattass, D. Roehl, A 3D sketch-based formulation to model salt bodies from seismic data, Computers \& Geosciences 142, 104457 (2020)

[14] C. Turgut, L. Jason, L. Davenne, Structural-scale modeling of the active confinement effect in the steel-concrete bond for reinforced concrete structures, Finite Elements in Analysis and Design 172, 103386 (2020)

[15] Q. Zhao, C.-M. Fan, F. Wang, W. Qu, Topology optimization of steady-state heat conduction structures using meshless generalized finite difference method, Engineering Analysis with Boundary Elements 119, 13-24 (2020)

[16] O.V. Menshykov, M.V. Menshykova, I.A. Guz, Effects of crack closure and friction for linear crack under normal impact, Engineering Analysis with Boundary Elements 115, 1-9 (2020) 